\title{
Social Economics and Women Entrepreneurship-A Competency Approach
}

\author{
Purna Prabhakar Nandamuri, Vijayudu Gnanamkonda, Chakravarthi Koundinya \\ Department of Marketing, ICFAI Business School, IFHE University, Hyderabad, India \\ Email: prabhakar.nandamuri@ibsindia.org, vijayudug@ibsindia.org,chakravarthik@ibsindia.org
}

How to cite this paper: Nandamuri, P.P., Gnanamkonda, V. and Koundinya, C. (2019) Social Economics and Women Entrepreneurship-A Competency Approach. Theoretical Economics Letters, 9, 1235-1245. https://doi.org/10.4236/tel.2019.95080

Received: March 29, 2019

Accepted: May 14, 2019

Published: May 17, 2019

Copyright (๑) 2019 by author(s) and Scientific Research Publishing Inc. This work is licensed under the Creative Commons Attribution International License (CC BY 4.0).

http://creativecommons.org/licenses/by/4.0/

Open Access

\begin{abstract}
Purpose of the Study: The fundamental determinants of entrepreneurship are entrepreneur and the society and the interlinked categories of human, financial, and social capitals. The present study takes a competency approach to test the human capital of women to understand the reasons for disparity in entrepreneurship. Data/Methodology: 164 management students-102 male and 62 female, interested to take up entrepreneurial career, were administered with PEC Self-Rating Questionnaire and the responses were analyzed with ANOVA and $t$ test for difference between group means, followed by effect size measurement to derive practical significance of the relationship. Findings: Out of 13 entrepreneurial competencies tested, differences are observed for eight components and larger effect is observed only for two components while the mean differences were not more than 0.66 on a scale of 5.00. Originality: The originality lies in the findings that gender-specific competency-gap has been narrowing down in the Indian emerging economy.
\end{abstract}

\section{Keywords}

Social Economics, Entrepreneurship, Human Capital, Personal

Entrepreneurial Competency, Women Entrepreneurs

\section{Introduction}

The woman who follows the crowd will usually go no further than the crowd. The woman who walk alone is likely to find herself in places no one has been ever before, says Albert Einstein. Analysis of the way in which social economics and entrepreneurship can be used as a successful approach for development provides one of the most important topics of interest for researchers in the context of recent dynamics in the economic and social spheres. American Psychological Association reports that an individual's socioeconomic status can consi- 
derably impact their attitudes [1]. The most cherished belief that anyone, regardless of his or her social position, can make it to the top if he or she works hard, is so deep that even evidence to the contrary seems to do little to deter. Social stratification in society is done considering socioeconomic status (hereafter referred to as SES) as a logical basis. The two mostly discussed factors that negotiate with SES in determining relative status are gender and race/ethnicity [1]. SES can encompass the opportunities and privileges afforded to people within society. The emergent area of social economics explores the dynamics of individual behavior affected by group-level influences. Women are clustered in lower SES occupations compared with men globally, and get lower average incomes than men even at the same levels of education and occupation.

Entrepreneurship is developed in an encouraging and conducive environment. It is believed that the two foremost determinants of entrepreneurship are entrepreneur himself/herself and the society where in he/she discharges his/her functions [2]. Globally, women own around 40\% fewer businesses than men [3]. The hidden entrepreneurial talent of women has progressively been evolving with the wider deliberation of their role and economic status in the society [4]. Global GDP could rise by $\$ 1.5$ trillion which equals to two percent if women and men participate equally in entrepreneurial activity. If women participate in the labor force to the same degree as men, the global economy would increase by $26 \%$, equal to $\$ 28$ trillion by 2025 , almost equivalent to the combined GDPs of the US and China. Global activity would increase by $\$ 12$ billion, equivalent to the combined GDPs of Japan, Germany, and the UK, if every country matched the participation rates of the highest-performing countries in their region [5]. The diverse and complex reasons for disparity include differences in access to human, financial, and social capital.

Three categories of capital-human, financial, and social, are critical for entrepreneurial ventures and these are interlinked. Women are less able to take advantage of the available opportunities since they tend to be less likely than men to have access to them all [3]. Human capital refers to the knowledge, skills and experience an entrepreneur needs to draw on. Many initiatives are under way to provide the female entrepreneurs with greater access to financial and social capitals. The present study takes the prompt from the Boston Consulting Group findings by proposing that human capital is the primary resource that enables to exploit other available resources and attempts to test the human capital of women in the form of personal entrepreneurial competencies in comparison with their counterparts.

\section{Literature Review}

Successful women are more likely than successful men to own a business so they can pursue a personal passion and to make a positive impact on the world [6]. Zeffane [7] in the study carried out in United Arab Emirates reported no statistically significant difference on the overall entrepreneurial potential between 
males and females. The number of women growing their businesses has reached a tipping point. An impressive 24\% of all businesses valued beyond $\$ 1$ million, have more than 50\% women ownership in the USA [8]. Women are 1.17 times more likely than men to create social ventures rather than only economic ventures, and 1.23 times more likely to pursue environmental ventures than economic-focused ventures [9]. According to Cox Conserves [10], 70\% of women were committed to increasing the level of their sustainable activities against only $62 \%$ of the men. Gupta et al. [11] examined the role of socially constructed gender stereotypes and their influence on the entrepreneurial intentions of males and females and did not find statistically significant difference. Shinnar et al. [12] examined the culture and gender shaped entrepreneurial perceptions across three nations and reported significant gender differences in perception of barriers, though the gap was not consistent across cultures. Strobl et al. [13], in agreement with Shinnar et al. [12] reported that male students had more positive attitude towards entrepreneurship and stronger entrepreneurial intentions.

Thus several studies report that men feel themselves more efficient and oriented to create a new venture than women. The present study attempts to figure out the difference between two genders regarding entrepreneurial competencies. Entrepreneurial competencies and gender are studied separately during the past few decades. The present research attempts to fill the gap by integrating the competency approach with gender disparities in entrepreneurship.

\section{Theoretical Framework and Hypotheses Development}

Past research establishes that the existence of certain skills and capabilities, otherwise called entrepreneurial competencies, distinguish entrepreneurs from non-entrepreneurs. In this context, the most important contribution of McClelland et al. [14] was that the identification of relevant entrepreneurial competencies to predict business formation and success within and across cultures. They had developed a measuring instrument to measure the personal entrepreneurial competencies (PEC) among successful entrepreneurs by conducting the competency studies in Malawi, India and Ecuador during 1970s and 1980s and evolved a framework for describing the nature and levels of those competencies. The present study takes McClelland et al. [14] as the basis to evolve the hypotheses under the proposition that the Personal Entrepreneurial Competencies (here after referred as PEC) are the function of gender. The variables involved are defined as follows:

Gender. Gender refers to the culture specific roles and behaviour expected of men and women according to their biological sex. Basing on the cultural context, the two sexes tend to occupy different social roles and tend to develop different strategies to ensure their survival and reproductive success which ultimately resulted in to the division of labour.

The hypotheses are proposed by considering the thirteen personal entrepreneurial competencies identified by McClelland et al. [14] as dependent variables, 
and the impact of gender of an individual as an independent variable.

1) Initiative: The trait of taking the lead rather than waiting for others to start and acting out of choice rather than compulsion.

Hypothesis-1: Gender specific differences regarding the entrepreneurial competency of initiative among the male and female genders are not significant.

2) Sees and Acts on Opportunities. A mindset of looking for and seizing business opportunities from everyday experiences.

Hypothesis-2: Gender doesn't influence the competency of seeking and acting on opportunities of an individual.

3) Persistence: The quality of not giving up easily and striving continuously until success is achieved.

Hypothesis-3: Gender of an individual won't impact the competency of persistence in entrepreneurial endeavor.

4) Information Seeking: The ability to use contacts or information networks to obtain useful information and an overall openness to ideas and information.

Hypothesis-4: Gender has no bearing on the information seeking capability of an individual in the entrepreneurial context.

5) Concern for High Quality of Work. A desire to produce a top or better quality product or service and always compares own work favorably to that of others.

Hypothesis-5: Concern for high quality of work is not related to the gender of an individual.

6) Commitment to Work Contract: Accepts full responsibility for problems in completing a job and ready to make personal sacrifice or expends extraordinary effort to complete a lob.

Hypothesis-6: Individual persons are committed to work contract similarly despite their gender differences.

7) Efficiency Orientation: Always try to find ways to do things faster and at less cost.

Hypothesis-7: The gender of an individual won't affect the competency of efficiency orientation in work.

8) Systematic Planning: The strategic skill of developing plans, anticipating obstacles, finding and evaluating alternatives and taking a logical and systematic approach to planned activities.

Hypothesis-8: The competency of systematic planning is not gender specific among the individuals.

9) Problem Solving: Observing potential problems in the course of action, generating new ideas and innovative solutions.

Hypothesis-9: An individuals problem solving skills are not related to the gender.

10) Self-Confidence: Expressing confidence in his or her own ability to complete a task and relying on one's own capabilities to successfully manage the risks encountered in task accomplishment.

Hypothesis-10: Gender differences don't impact a person's self confidence levels. 
11) Assertiveness. Conveying emphatically one's vision and convincing others of its value, directly tells others what they have to do and disciplines those failing in performance.

Hypothesis-11: All people are uniformly assertive irrespective of their gender specific variations.

12) Persuasion: Convincing others to support him or her and eliciting support of others in the venture.

Hypothesis-12: Persuasion skill is common across all individuals despite the gender differences.

13) Use of Influence Strategies. Acts to develop business contacts and uses influential people as agents to accomplish own objectives.

Hypothesis-13: People use influence strategies in entrepreneurial efforts irrespective of gender.

Summing all the thirteen hypotheses, the final hypothesis of the study is framed as follows:

Hypothesis-14: An individual s personal entrepreneurial competencies are not influenced by the gender of that person.

Based on the theoretical background and the resultant hypotheses, the proposed model for this study is shown in Figure 1.

\section{Research Objective}

In view of the indispensable need for understanding the role of the human capital in social economics, the present study aims to retest the thirteen components of the PEC identified and validated by McClelland et al. [14], for gender influence on the potential entrepreneurs, in the changed economic environment. Way back in 1987, the researchers had declared that all 13 components are capable of being demonstrated by persons who had not yet started businesses and these competencies might be used to assess potential 1 entrepreneurs. Further, the researchers found no gender differences in acquiring and practicing these competencies. However, further research is needed to determine whether the findings can be generalized to other cultures and other time periods and other generations.

\section{Methodology}

Sample: A sample of 164 students, who indicated beforehand that they were 0

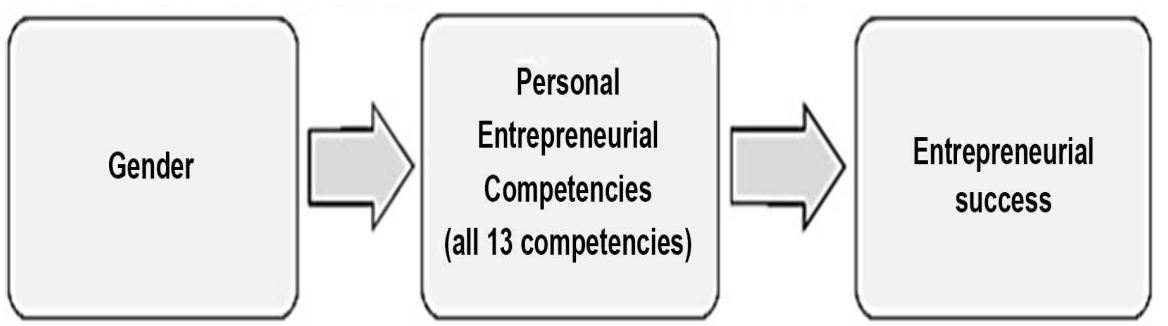

Figure 1. Entrepreneurial success model. 
interested in taking up entrepreneurship, among a population of around 60 final year post-graduate management students from two universities-one in Hyderabad in the State of Telangana, and the other in Vijayawada, in the State of Andhra Pradesh, were selected. The sample comprises of 102 male and 62 female students.

Method: The participants were administered with Personal Entrepreneurial Competency (PEC) Self-Rating Questionnaire, containing 65 items, adopted from McClelland et al. [14], with Likert scale ranging from not at all (1) to very well (5).

Variables: The variables considered for this study are a) gender as independent variable and $b$ ) the 13 components of personal entrepreneurial competency as dependent variables.

Hypothesis: Based on the theoretical framework, a total of 14 hypotheses-13 regarding each component of the PEC and one regarding the PEC as a holistic construct are developed.

Research Model and Hypotheses. The present study utilizes the quantitative model involving review of literature to formulate a total of 14 hypotheses which were tested statistically and the inferences were made basing on the findings.

Statistical Tools. The final responses were statistically tested with ANOVA and $t$ test, followed by effect size measurement for understanding the degree of influence of gender on the components of PEC of the potential individuals.

\section{Results and Analysis}

Gender is defined in terms of two categories-male and female. The Personal Entrepreneurial Competency (PEC) Self-Rating Questionnaire contains 65 items accounting to 13 specific competencies, where each specific competency has five statements answered by respondents on the Likert scale. To make the analysis simple, precise and more focused, the five statements pertaining to each competency are transposed into a single variable by its name with the help of SPSS. Then, the variances and specific differences between the two categories of gender and each competency are discussed in detail.

\section{Discussion}

Variance: Since the number of sample per each gender group are unequal (lopsided designs), the data is first subjected to Brown-Forsythe test, a more appropriate test in this context, is applied and the null hypothesis (of equal variances) for eight components is rejected and the alternative hypothesis that there are differences of varying degrees between the variances in the population is taken for consideration (Table 1).

At the initial level of analysis, one-way ANOVA test is applied (Table 2) to observe the degrees of difference between the two gender groups on the eight components which proved positive for variances. The analysis yielded highly significant $\mathrm{F}$ values representing noteworthy differences between the mean squares of the two groups on all the components. 
Table 1. Robust tests of equality of means.

\begin{tabular}{|c|c|c|c|c|c|}
\hline & & Statistic ${ }^{\mathrm{a}}$ & df1 & df2 & Sig. \\
\hline Initiative & Brown-Forsythe & 23.019 & 1 & 146.578 & 0.000 \\
\hline Sees \& acts on Opportunities & $"$ & 30.429 & 1 & 145.091 & 0.000 \\
\hline Persistence & $"$ & 22.010 & 1 & 144.652 & 0.000 \\
\hline Information Seeking & $”$ & 0.052 & 1 & 151.473 & 0.820 \\
\hline Concern for High Quality of Work & $"$ & 0.449 & 1 & 120.049 & 0.504 \\
\hline Commitment to Work Contract & $”$ & 27.703 & 1 & 155.008 & 0.000 \\
\hline Efficiency Orientation & $"$ & 0.149 & 1 & 152.424 & 0.700 \\
\hline Systematic Planning & $”$ & 0.007 & 1 & 155.632 & 0.936 \\
\hline Problem Solving & $”$ & 0.086 & 1 & 153.277 & 0.770 \\
\hline Self-Confidence & $"$ & 23.980 & 1 & 148.086 & 0.000 \\
\hline Assertiveness & $"$ & 43.632 & 1 & 138.576 & 0.000 \\
\hline Persuasion & & 13.206 & 1 & 154.026 & 0.000 \\
\hline Use of Influence Strategies & & 9.399 & 1 & 152.478 & 0.003 \\
\hline P E C as a single variable & & 21.071 & 1 & 151.533 & 0.000 \\
\hline
\end{tabular}

a. Asymptotically F distributed. Source: SPSS output.

Table 2. ANOVA\& $\mathrm{t}$ test readings.

\begin{tabular}{|c|c|c|c|c|c|c|c|}
\hline & & \multicolumn{2}{|c|}{ ANOVA } & \multicolumn{3}{|c|}{ t-test for Equality of Means } & \multirow{2}{*}{$\begin{array}{l}\text { Effect Size } \\
\text { Cohen's 'd" }\end{array}$} \\
\hline & & $\mathrm{F}$ & Sig. & $\begin{array}{c}\text { Mean } \\
\text { Difference }\end{array}$ & $\mathrm{t}$ & $\begin{array}{c}\text { Sig. } \\
\text { (2-tailed) }\end{array}$ & \\
\hline 1 & Initiative (1) & 21.078 & 0.000 & 0.49583 & 4.591 & 0.000 & 0.72 \\
\hline 2 & Sees \& Acts on Opportunities & 28.084 & 0.000 & 0.54889 & 5.299 & 0.000 & 0.83 \\
\hline 3 & Persistence (2) & 20.361 & 0.000 & 0.49317 & 4.512 & 0.000 & 0.70 \\
\hline 4 & Commitment to Work Contract & 24.116 & 0.000 & 0.37438 & 4.911 & 0.000 & 0.77 \\
\hline 5 & Self-Confidence (3) & 21.778 & 0.000 & 0.50620 & 4.667 & 0.000 & 0.73 \\
\hline 6 & Assertiveness & 41.625 & 0.000 & 0.66275 & 6.452 & 0.000 & 1.01 \\
\hline 7 & Persuasion & 11.573 & 0.001 & 0.25484 & 3.402 & 0.001 & 0.53 \\
\hline 8 & Use of Influence Strategies & 8.319 & 0.004 & 0.23517 & 2.884 & 0.004 & 0.45 \\
\hline 9 & $\mathrm{PE} \mathrm{C}$ as a single variable & 18.759 & 0.000 & 0.27654 & 4.331 & 0.000 & 0.68 \\
\hline
\end{tabular}

Source: SPSS output.

Difference between Group Means. After observing the significant differences between the groups, it is logically imperative to quantify the observed differences and to trace out the direction of the preferences. The $t$ test results for all the eight components prove significant confirming the observed variances through ANOVA. The wider difference of group means are observed for the component of assertiveness (0.66), followed by another competency of sees and acts on opportunities (0.55) and the lowest gap is evident on the component of 
use of influence strategies (0.23) with a precedence to persuasion (0.25) on a scale of 5.00, with the means of the other four competencies hover in between these extremes (Table 2). Further the positive nature of all the results indicates that the male groups mean values are higher than their counterparts on all the eight components.

Effect Size: In case of ANOVA results, it is always probable to watch a statistical significance but a low effect size simultaneously. Such phenomenon represents the existence of an association between the two variables, but that the issue is the practical significance of the relationship evident. Thus, the significant p-values only aren't adequate to point out the volume of an effect. Hence, it is essential to illustrate the extent of the effect for the cases with closer group means. Statistically, the Cohen's d technique homogenizes the effect size measurement, based on the derived $t$ values and degrees of freedom of the relevant cases, at three levels, in terms of the d value $\leq 0.20$ is a small effect size, $\geq 0.50$ is a moderate effect size and $\geq 0.80$ is a large effect size [15] (Table 3 ).

In the present study, the $\mathrm{d}$ values higher than the specified 0.80 standard, are evident for the components of assertiveness (1.01) and sees and acts on opportunities (0.83) indicating a large effect that more than $25 \%$ of the group members differ on theses competencies. The lowest $d$ reading $(0.45)$ for "use of influence strategies" lies in the range of 0.20 to 0.50 on the standard, inferring that a maximum up to $10 \%$ of the group members differ on this competency. And the remaining five components fall under the range of moderate effect indicating that the differences exist up to a maximum of $25 \%$ of the members of the two gender groups. These results are in sync with the observed mean differences during the $t$ test. Thus, the Cohen's $d$ analysis confirms with the $t$ test while quantifying the size of differences.

The Direction of the Differences: Finally, after analyzing and quantifying the differences to the size of effect, it is important to observe the direction of the differences between the two groups regarding the eight components of the personal entrepreneurial competency, proved significant, during the variance analysis. The direction and nature of differences can be observed from a graphic representation of the mean values of the two groups on the eight competencies through a clustered "box plot".

While the total sample mean stands at 3.04 on a scale of 5.00 , the group mean values of the male group stands above the sample mean (Figure 2) except for the competency of "use of influence strategies", whereas the mean values of the

Table 3. Percentage of variance explained.

\begin{tabular}{ccc}
\hline "d" & Standardized mean difference & Percentage of variance explained \\
\hline Small & 0.20 & $1 \%$ \\
Moderate & 0.50 & $10 \%$ \\
Large & 0.80 & $25 \%$ \\
\hline
\end{tabular}

Source: Cohen (1988). 


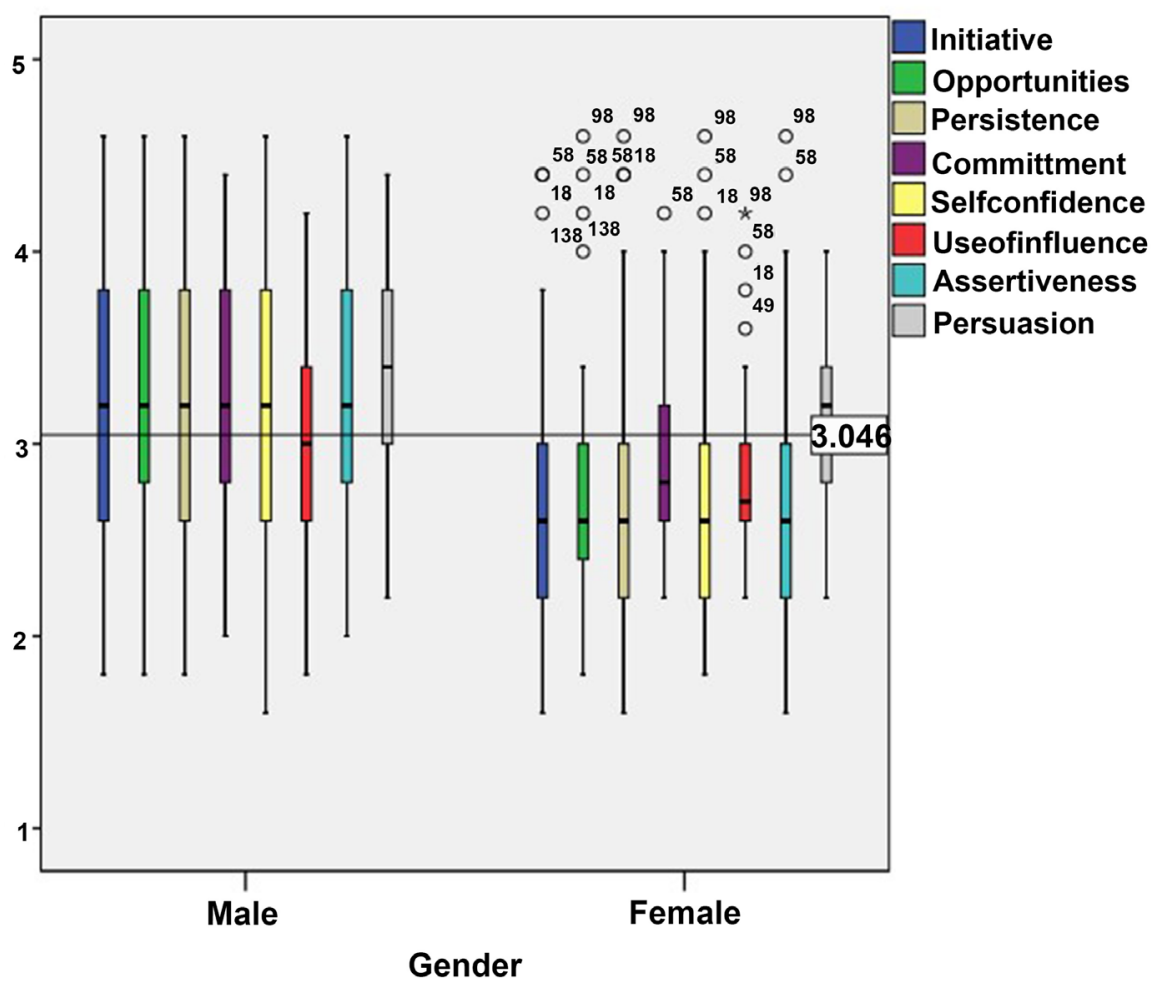

Figure 2. Group mean values. Source: SPSS output.

female group stand well below the sample mean, establishing a clear trail of the female group means from male group mean values. However, the mean differences are not more than 0.66 out of a scale of 5.00 (Table 2; Figure 2).

\section{Conclusions}

Way back in 1987, Mc Clelland [14] and his associates found no differences between the male and female groups on any of the 13 components of PEC. But, no study, after that, has supported the hypothesis, in similar context, in India. Even though, some studies found no difference, they have been conducted with diverse objectives and used different tools. But, the present study is conducted with a focused objective of measuring the gender impact on the personal entrepreneurial competencies of the potential entrepreneurs. Out of 13 components of PEC, five competencies-Information Seeking; Concern for High Quality of Work; Efficiency Orientation; Systematic Planning; and Problem Solving, were found to be uniform across the sample irrespective of the gender variation, implying that the gender specific variance has gradually been fading away among the educated youth, on these five aspects. However, the observed gender-specific competency-gap also has been narrowing down as observed from the effect size analysis and the graphical presentation of the group means through box plot.

The results of the present study, neither totally confirm with the literature that argued for gender specific variances, nor support the school of researchers that proposed no difference at all. Rather, the results present a true picture of the In- 
dian educated youth who wish to be potential entrepreneurs, by bringing out the vanishing gender oriented variances on the components of information, quality, efficiency, planning and problem solving, which are more or less the essential skills of the educated, that too, management graduated youth. However, the females are improving gradually and moving closer to their counterparts on the remaining eight competencies as the observed differences are narrower, even though significant. Probably, after some time, these smaller differences also may vanish and hopefully, there might be a time where no variance can be observed between the two genders regarding the personal entrepreneurial competencies. Thus, the study concludes that women are neither different nor inferior from male gender as human capital to exploit the financial and social capitals essential for entrepreneurship development. Hence it is up to the public governance systems to provide equal opportunities regarding financial and social capital to women.

Limitations of the Study: Even though the present research provides precious insights into the construct of personal entrepreneurial competency, some limitations, still, persist.

a) Design limitation: The modus operandi followed and the explicit constraints regarding the sample of the study may certainly have an effect on the outcomes.

b) Impact limitation: Even though utmost care is taken to ensure the most suitable design and appropriate statistical tools, some constraints may surface due to the regional concentration of the sample and being too population-specific nature.

c) Data limitation: Despite the richness of the results, there lies a possibility of underpowered results due to the incapability to collect as pertinent data as proposed since the enrollment was more difficult than was anticipated.

Scope for Further Research: The constraints mentioned in the study understandably provide the scope for further research in the same area. Carrying out a comparable study supported by a stronger and accurate design, sample and procedures is always possible. Further, a similar work may well be organized with a larger sample and a wider geography surpassing the regional and national boundaries. Further, the scope for a much representative sample to yield stronger results is always alive for further research. However, the study can be extended in several ways to supplement the domain literature of personal entrepreneurial competencies.

\section{Conflicts of Interest}

The authors declare no conflicts of interest regarding the publication of this paper.

\section{References}

[1] American Psychological Association ((2007)) Task Force on Socioeconomic Status. 
Report of the APA Task Force on Socioeconomic Status, Author, Washington DC. https://www.apa.org/pi/ses/resources/publications/task-force-2006.pdf

[2] Baum, J.R., Frese, M. and Baron, R.A. (2014) Entrepreneurship as an Area of Psychology Study: An Introduction. In: The Psychology of Entrepreneurship, Psychology Press, Hove, 33-50.

[3] BCG (2014) Bridging the Entrepreneurship Gender Gap-The Power of Networks. The Boston Consulting Group, Boston.

https://www.bcg.com/en-in/publications/2014/bridging-entrepreneurship-gender-g ap.aspx

[4] Resia, B. (2000) Problems Encountered in Promoting Women Enterprises in Women Entrepreneurship Edited by K. Sasikumar. Vikas Publishing House Pvt. Ltd., New Delhi.

[5] McKinsey (2015) The Power of Parity: How Advancing Women's Equality Can Add $\$ 12$ Trillion to Global Growth.

https://www.mckinsey.com/ /media/McKinsey/Featured\%20Insights/Employment \%20and\%20Growth/How\%20advancing\%20womens\%20equality\%20can\%20add\%2 012\%20trillion\%20to\%20global\%20growth/MGI\%20Power\%20of\%20parity_Full\%2 0report_September\%202015.ashx

[6] USTRUST (2013) 2013 U.S. Trust Insights on Wealth and Worth ${ }^{\mathrm{TM}}$-Annual Survey of High Net Worth and Ultra High Net Worth Americans.

http://doingmorethatmatters.com/wp-content/uploads/2013/09/2013-UST-Insights -Wealth-and-Worth-Full-Report.pdf

[7] Rachid, Z. (2013) Gender and Youth Entrepreneurial Potential: Evidence from the United Arab Emirates. International Journal of Business and Management, 8, 60-72. https://doi.org/10.5539/ijbm.v8n1p60

[8] Forbes (2016) Women Entrepreneurs Fuel Social Change and Economic Growth. https://www.forbes.com/sites/geristengel/2016/02/03/women-entrepreneurs-fuel-so cial-change-and-economic-growth/\#3b8014692c59

[9] Karen, H.D. and Jennifer, J.E. (2012) Global Women's Entrepreneurship Research-Diverse Settings, Questions and Approaches. Edward Elgar Publishing, Cheltenham.

[10] Cox Conserves (2007) Communities Sustainability Survey. https://www.coxenterprises.com/cox-conserves/communities/sustainability-survey

[11] Gupta, V.K., Goktan, A.B. and Gunay, G. (2014) Gender Differences in Evaluation of New Business Opportunity: A Stereotype Threat Perspective. Journal of Business Venturing, 29, 273-288. https://doi.org/10.1016/j.jbusvent.2013.02.002

[12] Rachel, S.S., Oliver, G. and Frank, J. (2012) Entrepreneurial Perceptions and Intentions: The Role of Gender and Culture. Entrepreneurship: Theory and Practice, 36, 465-494. https://doi.org/10.1111/j.1540-6520.2012.00509.x

[13] Andreas, S., Christoher, K. and Mike, P. (2012) Entrepreneurial Attitudes and Intentions: Assessing Gender Specific Differences. International Journal of Entrepreneurship and Small Business, 15, 452-468. https://doi.org/10.1504/IJESB.2012.046475

[14] McClelland, D.C., Richard, M.S., Spencer Jr., M.L. and Jose, S. (1987) The Identification and Assessment of Competencies and Other Personal Characteristics of Entrepreneurs in Developing Countries. The United States Agency for International Development, Washington DC. http://pdf.usaid.gov/pdf_docs/Pdaav866.pdf

[15] Cohen, J. (1988) Statistical Power Analysis for the Behavioral Sciences. 2nd Edition, Lawrence Earlbaum Associates, Hillsdale, 21-23. 